\title{
First Isolation, Antifungal Susceptibility, and Molecular Characterization of Cryptococcus neoformans from the Environment in Croatia
}

\author{
Donjeta Pllana-Hajdari ${ }^{1, *}$, Massimo Cogliati ${ }^{2}$, Ljiljana Čičmak ${ }^{3}$, Sanja Pleško ${ }^{4}$, \\ Emilija Mlinarić-Missoni ${ }^{3}$ and Ivana Mareković ${ }^{4, *}$ \\ 1 Department of Molecular Microbiology, National Institute of Public Health, 10000 Prishtina, Kosovo \\ 2 Laboratorio di Micologia Medica, Dipartimento Scienze Biomediche per la Salute, Università degli Studi di \\ Milano, 20133 Milano, Italy; Massimo.cogliati@unimi.it \\ 3 Department for Parasitology and Mycology, Croatian Institute for Public Health, 10000 Zagreb, Croatia; \\ ljiljana.cicmak@hzjz.hr (L.Č.); emilija.mlinaric.missoni@gmail.com (E.M.-M.) \\ 4 Department of Clinical and Molecular Microbiology, University Hospital Centre Zagreb, \\ University of Zagreb School of Medicine, 10000 Zagreb, Croatia; sanja.plesko@kbc-zagreb.hr \\ * Correspondence: donjetapllana@hotmail.com (D.P.-H.); imarekov@kbc-zagreb.hr (I.M.); \\ Tel.: +383-44-163-645 (D.P.-H.); +385-1-2367-319 (I.M.)
}

Received: 22 August 2019; Accepted: 10 October 2019; Published: 12 October 2019

\begin{abstract}
The purpose of this study was to investigate the presence of Cryptococcus neoformans species complex isolates from environmental sources in Croatia and to determine their molecular types and antifungal susceptibility. Swab samples of tree hollows and bird excreta in the soil beneath trees were collected. Samples included $472(92.73 \%)$ samples obtained from tree hollows and 37 (7.27\%) samples from bird excreta. Four $C$. neoformans species complex isolates were recovered from tree hollow swabs along the Mediterranean coast, while there were no isolates recovered from bird excreta or from the continental area. Three isolates were identified as molecular types VNI and one as VNIV. All tested antifungals showed high in vitro activity against the four isolates. This is the first report proving the presence of $C$. neoformans species complex in the environment of Croatia. The results of the study suggest a major risk of exposure for inhabitants living along the Croatian coast and that both VNI and VNIV molecular types can be expected in clinical cases of cryptococcosis. Susceptibility to antifungals confirmed that no resistance should be expected in patients with cryptococcosis at the present time.
\end{abstract}

Keywords: Cryptococcus neoformans; environment; molecular types; antifungal susceptibility

\section{Introduction}

The encapsulated basidiomycetous yeasts of Cryptococcus neoformans and C. gattii species complexes are infectious agents of cryptococcosis, a life-threatening infection primarily affecting immunocompromised hosts [1]. While the $C$. neoformans species complex mainly affects patients with acquired immunodeficiency syndrome (AIDS) and those who are immunosuppressed (transplant patients, those on long-term corticosteroids, and those prescribed monoclonal antibodies), one-quarter of patients with C. gattii species complex infections are immunocompetent and healthy. Infection of the brain and meninges by the $C$. neoformans species complex is the most important clinical manifestation in immunosuppressed individuals [2,3]. An estimated 220,000 cases of cryptococcal meningitis complicate HIV/AIDS worldwide each year, resulting in nearly 181,000 deaths annually [3,4].

Infections by Cryptococcus species are acquired from environmental sources and are a consequence of the inhalation of dehydrated blastoconidia or basidiospores into the lungs. The yeasts have been 
isolated from bird excreta, soil, bark and trunk hollows of trees, and decaying wood in various parts of the world [5].

The use of antifungal agents, particularly in long-term suppressive regimens, has raised concerns about the development of drug resistance in C. neoformans species complex [6]. Globally, fluconazole-resistant strains of $C$. neoformans species complex have been increasingly reported in the past two decades. Geographical distribution shows that increasing fluconazole resistance is demonstrated in Africa, Asia, and Latin America, while low rates are still found in North America and Europe, except for Spain [6-8]. In Croatia, the clinical isolates investigated in one study showed no resistance either to fluconazole or other antifungals [9]. A few studies reporting the antifungal susceptibility of environmental C. neoformans species complex strains have been conducted, mainly in Brazil and India [10-12]. Such studies are significant because the susceptibility data of environmental isolates may influence the profiles of the clinical isolates recovered from patients because of the transmission pathway from environmental sources. However, such studies from Europe are lacking.

The taxonomy of $C$. neoformans is still under major investigation [13-16]. The term "species complex" is used to comprise all genetic, pathogenic, epidemiological, ecological, and clinical differences between the strains [14]. C. neoformans species complex currently consists of five major molecular types distinguishable by several molecular techniques [17-21]: VNI, VNII, and VNB, with capsular antigen A (serotype A) and classified as C. neoformans var. grubii, VNIV with capsular antigen D (serotype D) and classified as C. neoformans var. neoformans, and VNIII, including diploid and aneuploid hybrids between the two varieties (AD hybrids). Molecular epidemiology data are important because they enable us to understand the population structure of the pathogen, its evolution, and how it is spreading across continents. In Europe, most cases of cryptococcosis are caused by isolates of the $C$. neoformans species complex, with VNI being the most prevalent molecular type, followed by VNIV and VNIII $[5,22]$. Genotyping of 48 clinical isolates obtained from 15 patients in Croatia was performed by amplified fragment length polymorphism (AFLP), showing a prevalence of $40 \%$ AFLP1/VNI, $40 \%$ AFLP2/VNIV, and 20\% AFLP3/VNIII isolates [9]. At present, C. neoformans species complex strains from environmental sources in Croatia have not yet been isolated or investigated for antifungal susceptibility and molecular epidemiology.

The purpose of this study was to investigate the presence of $C$. neoformans species complex isolates from environmental sources in Croatia and to determine their molecular types and antifungal susceptibility. The research results will provide the first insights into the ecology of Cryptococcus species in Croatia and thus the potential exposure risk of the inhabitants to these yeasts in the investigated urban locations. The antifungal susceptibility profile of $C$. neoformans isolated from environmental sources can indicate the susceptibility of clinical isolates and lead to the development of treatment guidelines.

\section{Materials and Methods}

\subsection{Geographic and Climate Characteristics of Croatia}

The geography of Croatia is defined by its location in southeastern Europe along the Mediterranean coast (Figure 1). Due to this location at the meeting point of the Mediterranean, the Alps, and the Pannonian plain, Croatia exhibits great geographical and natural diversity. The largest part of Croatia has a moderately warm rainy climate under the Köppen classification, with a mean monthly temperature in the coldest month of the year above $-3^{\circ} \mathrm{C}$ and below $18^{\circ} \mathrm{C}$ [23].

\subsection{Sample Collection, Cultures, and Identification}

Swab samples of tree hollows and bird excreta in the soil beneath trees were collected from different geographical areas in Croatia. Trees involved were identified to the species level whenever possible. The samples were collected from urban public places including squares, parks, gardens, hospital areas, and school playgrounds. Collecting and processing of swab samples was performed as described elsewhere [24]. Samples were cultured onto plates containing Niger seed agar incubated 
at $27^{\circ} \mathrm{C}$ and $37^{\circ} \mathrm{C}$ for two weeks and were monitored daily. The dark brown colonies suggestive of cryptococcal colonies were subcultured on Sabouraud peptone dextrose agar plates (Liofilchem, Roseto degli Abruzzi, Italy). The number of brown colonies appearing on each culture plate was counted and recorded. Identification of $C$. neoformans by conventional mycological methods included the commercial identification system ID 32 C (BioMérieux, Marcy l'Etoile, France) based on the assimilation of carbohydrates and nitrate as well as the presence of capsule observed in India ink preparations. Up to 10 cryptococcal yeast colonies were stored in glycine buffer at $-20{ }^{\circ} \mathrm{C}$ until antifungal susceptibility testing and molecular analysis were performed.

\subsection{Antifungal Susceptibility Testing}

Antifungal susceptibility of $C$. neoformans species complex isolates to flucytosine, amphotericin B, fluconazole, itraconazole and voriconazole were determined by ATB FUNGUS 3 (BioMérieux, Marcy l'Etoile, France). The test was performed according to the manufacturer's instructions. Isolates were also tested with a standard broth microdilution method according to the Clinical Laboratory Standards Institute (CLSI) for amphotericin B, fluconazole, and voriconazole [25]. Since there are no clinical breakpoints defined by the CLSI for C. neoformans species complex, epidemiological cutoff values (ECV) were used as reference values to define a strain as wild type or non-wildtype [26,27]. Isolates were considered wild type when the minimal inhibitory concentration (MIC) value for amphotericin $B$ was $\leq 0.5 \mu \mathrm{g} / \mathrm{mL}$, for flucytosine $\leq 8 \mu \mathrm{g} / \mathrm{mL}$, for fluconazole $\leq 8 \mu \mathrm{g} / \mathrm{mL}$, for itraconazole $\leq 0.25 \mu \mathrm{g} / \mathrm{mL}$, for voriconazole $\leq 0.25 \mu \mathrm{g} / \mathrm{mL}$. Susceptibility testing according to CLSI was done in 2019, two years after other investigations were already finished. For that reason, not all isolates (but two) were viable and available for testing.

\subsection{Molecular Analysis}

The molecular type and mating type of the isolates was determined by multiplex PCR, as previously described [18,28,29]. Strains H99 (VNI), WM626 (VNII), JEC21 (VNIV), and CBS 132 (VNIII) were included as reference strains [19].

\subsection{Statistical Analysis}

Statistical analysis included descriptive frequency tables, and Fisher's exact test. Statistical significance was determined when $p \leq 0.05$ was observed.

\section{Results}

\subsection{Distribution of Samples According to Location, Sample Type, and Tree Species}

A total of 509 swab samples was collected, covering a wide territory of Croatia during summer and autumn 2013-2016 (Figure 1). Fourteen Croatian towns were included in the study: Zagreb, Čakovec, Samobor, Varaždin, and Osijek in the continental area $(n=208,40.86 \%)$, and Split, Rijeka, Rovinj, Šibenik, Korčula, Krk, Pula, Dubrovnik, and Makarska along the Mediterranean coast $(n=301$, 59.13\%). Samples included 472 (92.73\%) swab samples from tree hollows and 37 (7.27\%) samples from bird excreta. A total of 46 different tree species were sampled (Table S1). Most of the trees were Olea europea (olive tree, 25.5\%), Ceratonia siliqua (carob tree, 5.3\%), Pinus sylvestris (scots pine, 5.1\%), Betula pendula (silver birch, $4.5 \%$ ), Castanea spp. (chestnut tree, $4.3 \%$ ), and Prunus dulcis (almond tree, $3.9 \%)[30]$. 


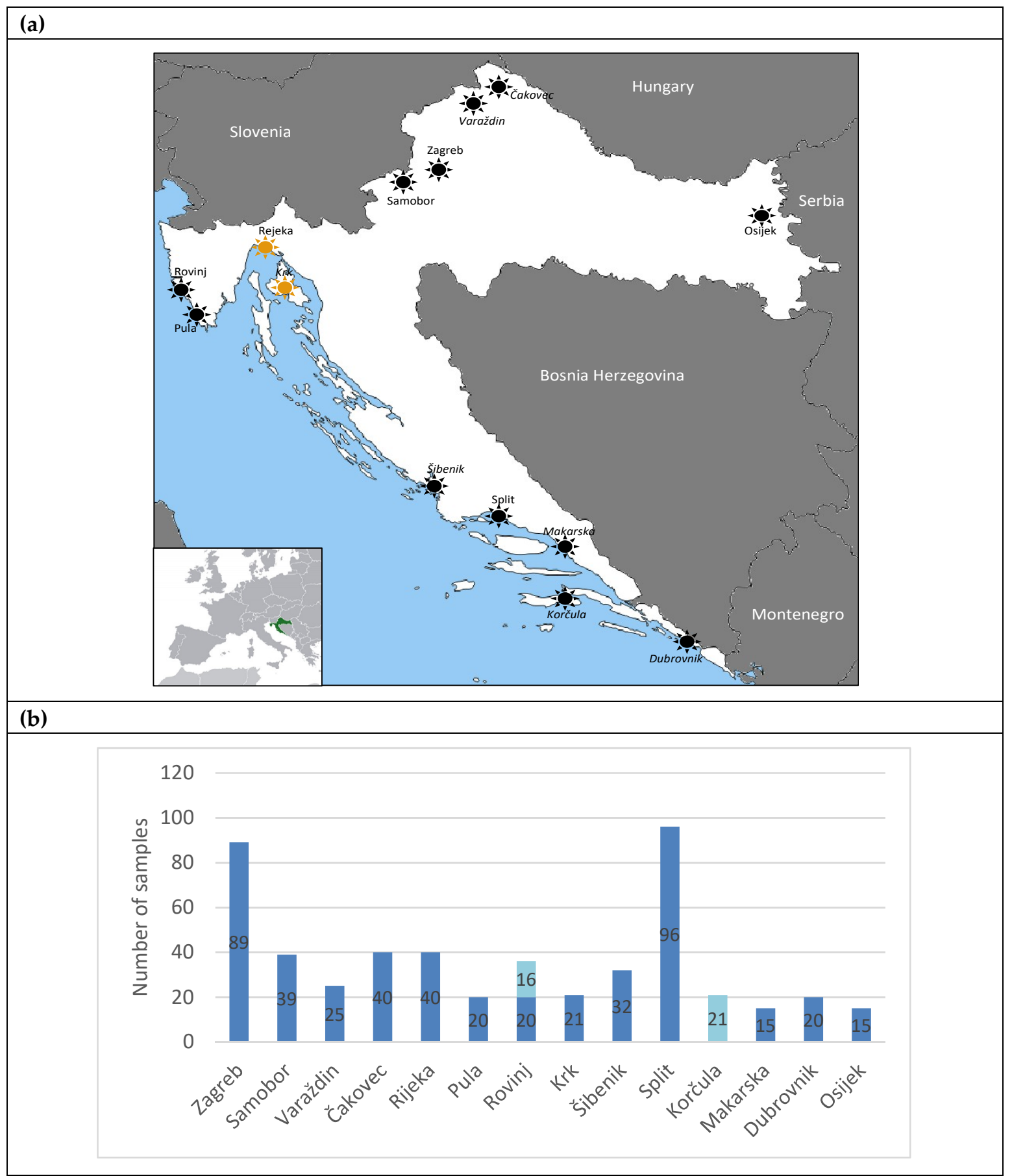

Figure 1. (a) The map represents the geographic distribution of the environmental samplings. Locations marked in yellow indicate the towns where positive samples were recovered. The inset shows the geographic position of Croatia in Europe. (b) The number and type of sample collected in each of the 14 sampling locations. Dark blue bars, samples from tree hollows; light blue bars, samples of bird excreta in the soil beneath the trees.

\subsection{Cryptococcus spp. Isolates in Environmental Samples}

Four $C$. neoformans species complex isolates were identified during this study (4/509, 0.8\%). All four isolates were recovered from cultures of tree hollow swabs collected in the Mediterranean area, while there were no isolates recovered from bird excreta or from samples collected in the continental 
area. The isolate from Rijeka was found in the hospital area and three isolates from the island of Krk were found along the promenade beside the sea.

Comparisons of positive samples between the two sample types, between samples collected in the Mediterranean and continental area, as well as between those recovered from olive trees and other tree species were not statistically significant.

\subsection{Molecular Characterization of C. neoformans Species Complex Isolates}

The four C. neoformans species complex isolates were classified into two different molecular types, VNI $(n=3)$ and VNIV $(n=1)$, all with mating type $\alpha$ (Figure 2$)$. The three VNI isolates originated from two locations, Rijeka and Krk Island, whereas the VNIV isolate was found on Krk Island. Three isolates were found in tree hollows of O. europea, while one VNI isolate was also found in a tree hollow of a P. sylvestris. The only isolate found in P. sylvestris tree hollows originated from the town of Rijeka and the isolates recovered from O. europea were found on Krk Island.

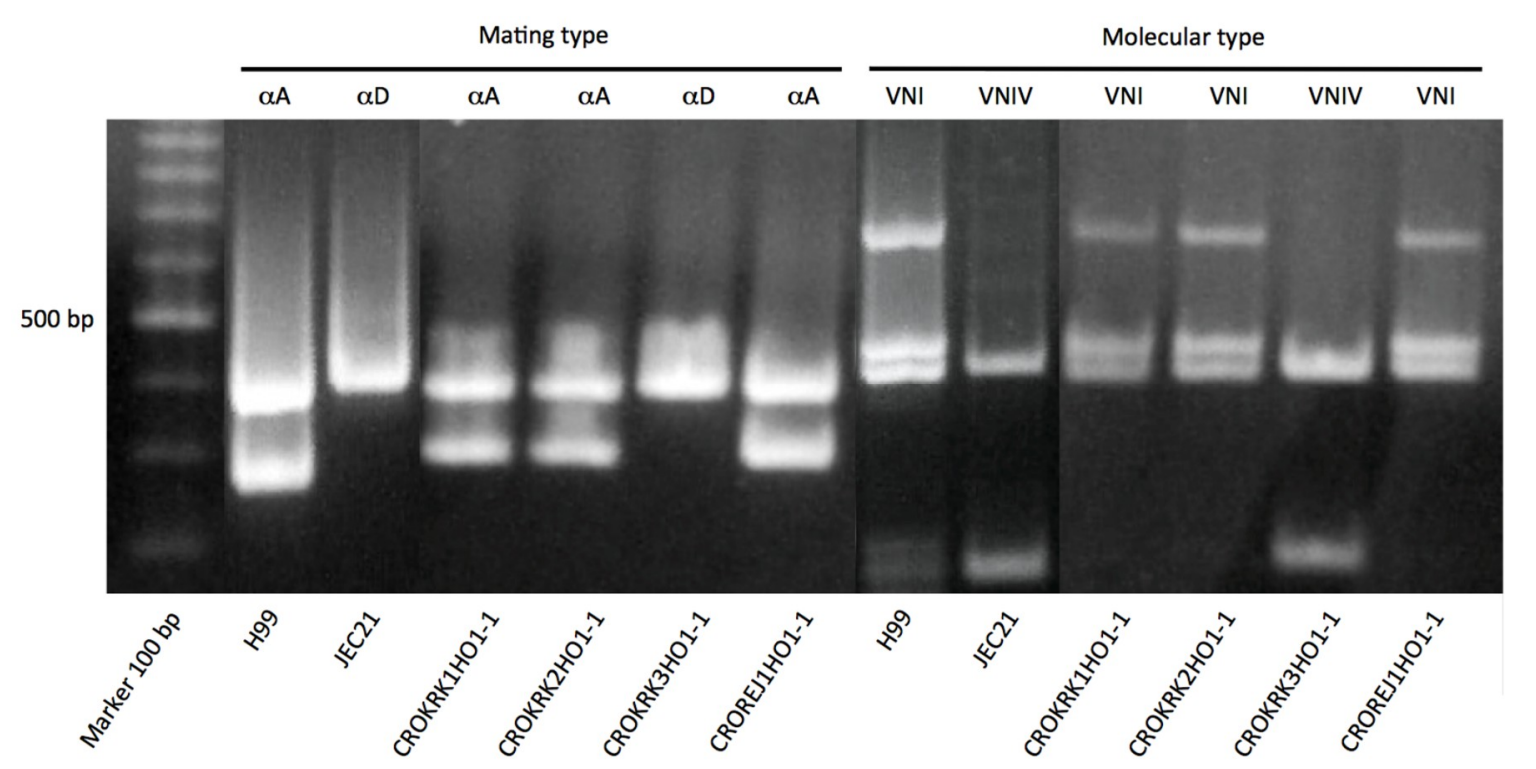

Figure 2. Multiplex PCR results showing mating type and molecular type identification of the four Croatian Cryptococcus neoformans species complex isolates. H99 and JEC21 represents the reference strains, VNI- $\alpha$ A and VNIV- $\alpha$ D, respectively. The 100 bp DNA ladder (Promega, Madison, WI, USA) was used as molecular DNA ladder. CROKRK = isolates from Krk Island; CROREJ = isolate from Rijeka.

\subsection{Antifungal Susceptibility of C. neoformans Species Complex Isolates}

Results obtained by the ATB FUNGUS 3 method showed that all isolates were as susceptible as wild-type strains, with MIC values very similar for all antifungals tested. Antifungal susceptibility according to the CLSI broth microdilution method, performed for one VNI and one VNIV isolate, confirmed the ATB FUNGUS 3 results (Table 1). 
Table 1. Antifungal susceptibility of the four C. neoformans species complex isolates tested by ATB FUNGUS 3 and broth microdilution reported as minimal inhibitory concentration values ( $\mu \mathrm{g} / \mathrm{mL})$.

\begin{tabular}{|c|c|c|c|c|c|c|c|c|c|c|c|}
\hline \multirow[t]{2}{*}{ Location } & \multirow[t]{2}{*}{$\begin{array}{c}\text { Molecular } \\
\text { Type }\end{array}$} & \multicolumn{2}{|c|}{$\begin{array}{c}5-\mathrm{FC} \\
(\mathrm{ECV}=8 \\
\mu \mathrm{g} / \mathrm{mL})\end{array}$} & \multicolumn{2}{|c|}{$\begin{array}{c}\text { AMB } \\
(\mathrm{ECV}=0.5 \\
\mu \mathrm{g} / \mathrm{mL})\end{array}$} & \multicolumn{2}{|c|}{$\begin{array}{c}\text { FLZ } \\
(\mathrm{ECV}=8 \\
\mu \mathrm{g} / \mathrm{mL})\end{array}$} & \multicolumn{2}{|c|}{$\begin{array}{c}\text { ITZ } \\
(\mathrm{ECV}=0.25 \\
\mu \mathrm{g} / \mathrm{mL})\end{array}$} & \multicolumn{2}{|c|}{$\begin{array}{c}\mathrm{VOZ} \\
(\mathrm{ECV}=0.25 \\
\mu \mathrm{g} / \mathrm{mL})\end{array}$} \\
\hline & & ATBF3 & CLSI & ATBF3 & CLSI & ATBF3 & CLSI & ATBF3 & CLSI & ATBF3 & CLSI \\
\hline Krk & VNIV & 4 & - & 0.5 & 0.25 & 1 & 4 & 0.125 & - & 0.06 & 0.25 \\
\hline Krk & VNI & 4 & - & 0.5 & - & 1 & - & 0.125 & - & 0.06 & - \\
\hline Krk & VNI & 4 & - & 0.5 & - & 1 & - & 0.125 & - & 0.06 & - \\
\hline Rijeka & VNI & 4 & - & 0.5 & 0.25 & 2 & 4 & 0.125 & - & 0.06 & 0.125 \\
\hline
\end{tabular}

5-FC = 5-fluorocytosine; $\mathrm{AMB}=$ amphotericin $\mathrm{B} ; \mathrm{FLZ}=$ fluconazole; $\mathrm{ITZ}=$ itraconazole; $\mathrm{VOZ}$ = voriconazole; $\mathrm{ECV}=$ epidemiological cutoff value; ATBF3 = ATB FUNGUS 3 method; CLSI = CLSI standard broth microdilution method; - = not tested.

\section{Discussion}

This is the first report showing the presence of $C$. neoformans species complex isolates from environmental sources in Croatia along with their antifungal susceptibility and molecular characterization, which were only available for clinical isolates so far [9]. However, studies had previously been conducted in an attempt to find C. neoformans species complex in the environment in this geographical area. An extensive environmental survey was carried out during 2012-2015, representing 12 countries with 6436 samples, which documented the distribution of $C$. neoformans and C. gattii species complexes around the Mediterranean basin. Croatia was represented with 18 environmental samples, but had no positive results [31]. Seasonal distribution cannot be the reason for not finding C. neoformans species complex in Croatia at the locations in the previous study because samples were collected each month by each of the collaborating groups. In that study, the peak of positive trees was observed during the spring. In our study, samples were also collected year-round, and all four isolates were found in May and June, which is in accordance with a previous study. However, the seasonal distribution cannot be analyzed because of the small number of positive samples [31].

In our study, $C$. neoformans species complex isolates were found only in the environmental from the Mediterranean part of Croatia. Their recovery from tree hollows of O. europea and P. sylvestris is in agreement with the aforementioned study investigating $C$. neoformans species' complex distribution around Mediterranean basin and demonstrating the presence of this species in samples from trees belonging mainly to the genera Eucalyptus, Olea, Ceratonia, and Pinus in Cyprus, France, Greece, Italy, Libya, Portugal, Spain, and Turkey [30]. Leaves and flowers were not sampled because in the study by Cogliati et al. no isolates were recovered from these sites [31].

Tree hollows, as an important environmental niche for $C$. neoformans species complex, have been investigated since the 1990s [32]. The affinity of Cryptococcus spp. with this environment had been explained in previous studies by its ability to produce laccase enzyme. Aside from the production of melanin, laccase is involved in the degradation of lignin, a polymer related to cellulose and an integral part of virtually all higher plants that provides rigidity to woody tissue [33]. In our study, VNI isolates were recovered from two tree species, O. europea and P. sylvestris, while the VNIV isolate was only recovered from O. europea. In a previous study involving the Mediterranean area, C. neoformans var. grubii colonized 12 different tree genera, confirming its ability to adapt to different environments and distribute globally. In contrast, C. neoformans var. neoformans showed a preference for trees typical of the subcontinental climate, such as Platanus, Prunus, and Quercus, probably reflecting its ability to tolerate lower temperature better than C. neoformans var. grubii. However, the climatic zones have unclear boundaries, enabling isolates belonging to different varieties to share the same tree species as a niche [31,34].

Although the authors intended to collect both types of samples (swab samples of tree hollows and bird excreta in the soil beneath trees) from every location where samples were collected, bird 
excreta were difficult to find. The streets in towns were cleaned every day and samples were collected early in the morning; bird excreta were found only in two locations, Rovinj and Korčula. This may be a sign to other researchers investigating $C$. neoformans species complex in the environment that the improvement of sample collection techniques for this purpose is needed. The birds from which excreta were collected were not identified.

Bird excreta, if collected at two locations, could be easily positive as well, assuming that both the birds and the decaying trees are an important part of the life cycle of the same organism, C. neoformans species complex. In the recent study by Springer et al., the authors demonstrated the broad importance of plants (and plant debris) as an ecological niche and reservoirs of infectious propagules of cryptococci in the environment. Cryptococci can undergo saprobic filamentation, mating, and the production of spores on dead plant material, indicating the potential for the long-term association of cryptococci with plant [35]. Therefore, it may be possible that birds are responsible for spreading, while plants may help with maintaining, optimizing, and enhancing virulence factors during the environmental lifecycle of this opportunistic pathogen.

The distribution of molecular types VNI and VNIV in the environmental samples in Croatia was expected according to previous studies. VNI is the most prevalent molecular type in the Mediterranean basin, distributed from Portugal to Libya [5]. Molecular type VNIV, although less common than VNI, was already detected in the environment of Croatia's neighboring countries, for example Italy [29,36]. In Greece, the VNIV is the most common molecular type, as well as in northern Turkey. Molecular types VNII, VNB, and VNIII were not detected in our study. So far, these types were detected in the Mediterranean basin from trees in Libya, Greece, and Turkey [29]. Although C. gattii species complex isolates were not found, their presence in Croatia, especially in the southern part of the country, cannot be excluded since this zone is characterized by a hot Mediterranean climate similar to that in the neighboring regions of southern Italy and Greece, where this pathogen has already been reported $[29,36]$.

The molecular analysis of environmental isolates in Croatia demonstrated the presence of molecular types VNI and VNIV, which were already identified in clinical samples during previous studies. Molecular type VNIII has only been detected in clinical samples so far $[5,9]$. The impact of different molecular types on patient outcome in terms of clinical manifestations or attributable mortality rates is still unknown. Controversial results have been generated regarding the correlation between molecular types, virulence, and mortality rate [37,38].

The tested antifungal compounds amphotericin B, 5-flucytosine, fluconazole, itraconazole, and voriconazole demonstrated high in vitro activity against environmental C. neoformans species complex isolates. This is in accordance with the antifungal susceptibility results for clinical isolates in a previous study in which all tested antifungals also showed high in vitro activity against $C$. neoformans isolates [9]. Some studies demonstrated differences in antifungal susceptibility among molecular types, but the correlation between the molecular type and antifungal susceptibility is still an open issue [39,40].

This is the first report proving the presence of $C$. neoformans species complex in the environment of Croatia. The results of the study show the potential risk of exposure for inhabitants, especially on the Croatian coast, to certain molecular types, particularly VNI and VNIV, which can be expected in clinical cases of cryptococcosis. Although a limitation of this study is the small number of detected environmental isolates, their antifungal susceptibility pattern suggests that no strains with low susceptibility to the most common antifungals should be expected in patients with cryptococcosis and no guideline modifications are needed at the moment. Further investigation regarding the correlation of molecular types with clinical outcome and antifungal susceptibility are warranted.

Supplementary Materials: The following are available online at http://www.mdpi.com/2309-608X/5/4/99/s1. Table S1: Number of samples collected from different tree species in Croatia.

Author Contributions: Conceptualization, M.C., E.M.-M. and I.M.; Data curation, D.P.-H.; Formal analysis, D.P.-H.; Funding acquisition, M.C., L.Č., E.M.-M. and I.M.; Investigation, D.P.-H.; Methodology, M.C., L.Č., S.P. and I.M.; Project administration, D.P.-H.; Resources, M.C., E.M.-M. and I.M.; Software, D.P.-H.; Supervision, M.C., 
E.M.-M. and I.M.; Validation, M.C. and I.M.; Visualization, D.P.-H., M.C. and I.M.; Writing—original draft, D.P.-H.; Writing-review \& editing, M.C., L.Č. and I.M.

Funding: This research was partially funded by Project action "Causes of fungal infection in immunocompromised patients", Croatian Institute for Public Health, approved by the Croatian Health Insurance Institute, Republic of Croatia, 2010-2012 and by Scientific research support of University of Zagreb "Prevalence of molds and antifungal susceptibility in hematological and other immunocompromised patients in respiratory tract specimens and their influence on antifungal use".

Acknowledgments: Authors would like to thank Verica Vazic-Babic for helping me with processing the samples and all others who helped me with collecting the samples in Croatia.

Conflicts of Interest: The authors declare no conflict of interest.

\section{References}

1. Mourad, A.; Perfect, J.R. Present and Future Therapy of Cryptococcus Infections. J. Fungi. 2018, 4, 79. [CrossRef] [PubMed]

2. George, I.A.; Spec, A.; Powderly, W.G.; Santos, C.A.Q. Comparative Epidemiology and Outcomes of Human Immunodeficiency virus (HIV), Non-HIV Non-transplant, and Solid Organ Transplant Associated Cryptococcosis: A Population-Based Study. Clin. Infect. Dis. 2018, 66, 608-611. [CrossRef] [PubMed]

3. Rajasingham, R.; Smith, R.M.; Park, B.J.; Jarvis, J.N.; Govender, N.P.; Chiller, T.M.; Denning, D.W.; Loyse, A.; Boulware, D.R. Global burden of disease of HIV-associated cryptococcal meningitis: An updated analysis. Lancet. Infect. Dis. 2017, 17, 873-881. [CrossRef]

4. Bongomin, F.; Gago, S.; Oladele, R.O.; Denning, D.W. Global and Multi-National Prevalence of Fungal Diseases-Estimate Precision. J. Fungi 2017, 3, 57. [CrossRef]

5. Cogliati, M. Global molecular epidemiology of Cryptococcus neoformans and Cryptococcus gattii: An atlas of the molecular types. Scientifica 2013. [CrossRef]

6. Pfaller, M.A.; Diekema, D.J.; Gibbs, D.L.; Newell, V.A.; Bijie, H.; Dzierzanowska, D.; Klimko, N.N.; Letscher-Bru, V.; Lisalova, M.; Muehlethaler, K.; et al. Results from the ARTEMIS DISK Global Antifungal Surveillance Study, 1997 to 2007: 10.5-Year Analysis of Susceptibilities of Noncandidal Yeast Species to Fluconazole and Voriconazole Determined by CLSI Standardized Disk Diffusion Testing. J. Clin. Microbiol. 2009, 47, 117-123. [CrossRef]

7. Chen, Y.C.; Chang, T.Y.; Liu, J.W.; Chen, F.J.; Chien, C.C.; Lee, C.H.; Lu, C.H. Increasing trend of fluconazole-non-susceptible Cryptococcus neoformans in patients with invasive cryptococcosis: A 12-year longitudinal study. BMC Infect. Dis. 2015, 15, 277. [CrossRef]

8. Perkins, A.; Gomez-Lopez, A.; Mellado, M.; Rodriguez-Tudela, J.L.; Cuenca-Estrella, M. Rates of antifungal resistance among Spanish clinical isolates of Cryptococcus neoformans var. neoformans. J. Antimicrob. Chemother. 2005, 56, 1144-1147. [CrossRef]

9. Mlinarić-Missoni, E.; Hagen, F.; Chew, M.H.W.; Važić-Babić, V.; Boekhout, T.; Begovac, J. In vitro antifungal susceptibilities and molecular typing of sequentially isolated clinical Cryptococcus neoformans strains from Croatia. J. Med. Microbiol. 2011, 60, 1487-1495. [CrossRef]

10. Guch, R.S.; Nawangel, S.R.; Singh, S.M.; Yadu, R.; Tiwari, A.; Gumasta, R.; Kavishwar, A. Antifungal susceptibility of clinical and environmental Cryptococcus neoformans and Cryptococcus gattii isolates in Jabalpur, a city of Madhya Pradesh in Central India. Braz. J. Microbiol. 2015, 46, 1125-1133. [CrossRef]

11. Chowdhary, A.; Randhawa, H.S.; Sundar, G.; Kathuria, S.; Prakash, A.; Khan, Z.; Sun, S.; Xu, J. In vitro antifungal susceptibility profiles and genotypes of 308 clinical and environmental isolates of Cryptococcus neoformans var. grubii and Cryptococcus gattii serotype B from north-western India. J. Med. Microbiol. 2011, 60, 961-967. [CrossRef] [PubMed]

12. Andrade-Silva, L.; Ferreira-Palm, K.; Mora, J.D.; da Silva, P.R.; Andrade, A.A.; Araujo, N.E.; Pedrosa, A.E.; Silva-Vergara, M.L. Susceptibility profile of clinical and environmental isolates of Cryptococcus neoformans and Cryptococcus gattii in Uberaba, Minas Gerais, Brazil. Med. Mycol. 2013, 51, 635-640. [CrossRef] [PubMed]

13. Hagen, F.; Khayhan, K.; Theelen, B.; Kolecka, A.; Polacheck, I.; Sionov, E.; Falk, R.; Parnmen, S.; Lumbsch, H.T.; Boekhout, T. Recognition of seven species in the Cryptococcus gattii/Cryptococcus neoformans species complex. Fungal Genet. Biol. 2015, 78, 16-48. [CrossRef] [PubMed] 
14. Kwon-Chung, K.J.; Varma, A. Do major species concepts support one, two or more species within Cryptococcus neoformans? FEMS Yeast Res. 2006, 6, 574-587. [CrossRef] [PubMed]

15. Hagen, F.; Lumbsch, H.T.; Arsic-Arsenijevic, V.; Badali, H.; Bertout, S.; Billmyre, R.B.; Bragulat, M.R.; Cabañes, F.J.; Carbia, M.; Chakrabarti, A.; et al. Importance of resolving fungal nomenclature: The case of multiple pathogenic species in the Cryptococcus genus. mSphere 2017, 2, e00238-17. [CrossRef] [PubMed]

16. Samarasinghe, $\mathrm{H} . ; \mathrm{Xu}, \mathrm{J}$. Hybrids and hybridization in the Cryptococcus neoformans and Cryptococcus gattii species complexes. Infect. Genet. Evol. 2018, 66, 245-255. [CrossRef] [PubMed]

17. Meyer, W.; Castañeda, A.; Jackson, S.; Huynh, M.; Castañeda, E. IberoAmerican Cryptococcal Study Group. Molecular typing of IberoAmerican Cryptococcus neoformans isolates. Emerg. Infect. Dis. 2003, 9, 189-195. [CrossRef]

18. Boekhout, T.; Theelen, B.; Diaz, M.; Fell, J.W.; Hop, W.C.J.; Abeln, E.C.A.; Dromer, F.; Meyer, W. Hybrid genotypes in the pathogenic yeast Cryptococcus neoformans. Microbiology 2001, 147, 891-907. [CrossRef]

19. Cogliati, M.; Allaria, M.; Tortorano, A.M.; Viviani, M.A. Genotyping Cryptococcus neoformans var. neoformans with specific primers designed from PCR-fingerprinting bands sequenced using a modified PCR-based strategy. Med. Mycol. 2000, 38, 97-103. [CrossRef]

20. Meyer, W.; Aanensen, D.M.; Boekhout, T.; Cogliati, M.; Diaz, M.R.; Asposto, M.C.; Fisher, M.; Gilgado, F.; Hagen, F.; Kaocharoen, S.; et al. Consensus multi-locus sequence typing scheme for Cryptococcus neoformans and Cryptococcus gattii. Med. Mycol. 2009, 47, 561-570. [CrossRef]

21. Meyer, W. Cryptococcus gattii in the Age of Whole-Genome Sequencing. MBio 2015, 6, e01761-15. [CrossRef] [PubMed]

22. Viviani, M.A.; Cogliati, M.; Esposto, M.C.; Lemmer, K.; Tintelnot, K.; Colom Valiente, M.F.; Swinne, D.; Velegraki, A.; Velho, R. European Confederation of Medical Mycology (ECMM) Cryptococcosis Working Group. Molecular analysis of 311 Cryptococcus neoformans isolates from a 30-month ECMM survey of cryptococcosis in Europe. FEMS Yeast Res. 2006, 6, 614-619. [CrossRef] [PubMed]

23. Environmental and macroeconomic impact assessment of different development scenarios to organic and low-input farming in Croatia. Available online: http://www.fao.org/docs/eims/upload/229899/2005_12_ doc02.pdf (accessed on 6 July 2019).

24. Randhawa, H.S.; Kowshik, T.; Khan, Z.U. Efficacy of swabbing versus a conventional technique for isolation of Cryptococcus neoformans from decayed wood in tree trunk hollows. Med. Mycol. 2005, 43, 67-71. [CrossRef] [PubMed]

25. Alexander, B.D.; Procop, G.W.; Dufresne, P.; Fuller, J.; Ghannoum, M.A.; Hanson, K.E.; Holliday, D.; Holliday, N.M.; Kovanda, L.; Lockhart, S.R.; et al. Reference Method for Broth Dilution Antifungal Susceptibility Testing of Yeasts, 4th ed.; Clinical and Laboratory Standards Institute: Wayne, PA, USA, 2017.

26. Espinel-Ingroff, A.; Aller, A.I.; Canton, E.; Castañón-Olivares, L.R.; Chowdhary, A.; Cordoba, S.; Cuenca-Estrella, M.; Fothergill, A.; Fuller, J.; Govender, N.; et al. Cryptococcus neoformans-Cryptococcus gattii Species Complex: An International Study of Wild-Type Susceptibility Endpoint Distributions and Epidemiological Cutoff Values for Fluconazole, Itraconazole, Posaconazole, and Voriconazole. Antimicrob. Agents Chemother. 2012, 56, 5898-5906. [CrossRef]

27. Espinel-Ingroff, A.; Chowdhary, A.; Cuenca-Estrella, M.; Fothergill, A.; Fuller, J.; Hagen, F.; Govender, N.; Guarro, J.; Johnson, E.; Lass-Flörl, C.; et al. Cryptococcus neoformans-Cryptococcus gattii species complex: An international study of wild-type susceptibility endpoint distributions and epidemiological cutoff values for amphotericin B and flucytosine. Antimicrob. Agents. Chemother. 2012, 56, 3107-3113. [CrossRef]

28. Esposto, M.C.; Cogliati, M.; Tortorano, A.M.; Viviani, M.A. Determination of Cryptococcus neoformans var. neoformans mating type by multiplex PCR. Clin. Microbiol. Infect. 2004, 10, 1092-1094. [CrossRef]

29. Cogliati, M.; Andrianarivelo, M.R.; Ellabib, M.; Nnadi, E.N.; Cornet, M. Molecular-Type Specific Multiplex PCR produces a distinct VNII PCR pattern among Cryptococcus neoformans species complex. Med. Mycol. 2019, 57, 384-386. [CrossRef]

30. San-Miguel-Ayanz, J.; de Rigo, D.; Caudullo, G.; Houston Durrant, T.; Mauri, A. European Atlas of Forest Tree Species; Publication Office of the European Union: Luxembourg, 2016.

31. Cogliati, M.; D’Amicis, R.; Zani, Z.; Montagna, M.T.; Caggiano, G.; De Giglio, O.; Balbino, S.; De Donno, A.; Serio, F.; Susever, S. Environmental distribution of Cryptococcus neoformans and C. gattii around the Mediterranean basin. FEMS Yeast Res. 2016, 16, fow045. [CrossRef] 
32. Lazera, M.S.; Salmito Calvacanti, M.A.; Londero, A.T.; Trilles, L.; Nishikawa, M.M.; Wanke, B. Possible primary ecological niche of Cryptococcus neoformans. Med. Mycol. 2000, 38, 379-383. [CrossRef]

33. Janusz, G.; Pawlik, A.; Sulej, J.; Swiderska-Burek, U.; Jarosz-Wilkolazka, A.; Paszczynski, A. Lignin degradation: Microorganisms, enzymes involved, genomes analysis and evolution. FEMS Microbiol. Rev. 2017, 41, 941-962. [CrossRef]

34. Cogliati, M.; Puccianti, E.; Montagna, M.T.; De Donno, A.; Susever, S.; Ergin, C.; Velegraki, A.; Ellabib, M.S.; Nardoni, S.; Macci, C.; et al. Fundamental niche prediction of the pathogenic yeasts Cryptococcus neoformans and Cryptococcus gattii in Europe. Environ. Microbiol. 2017, 19, 4318-4325. [CrossRef] [PubMed]

35. Springer, D.J.; Mohan, R.; Heitman, J. Plants promote mating and dispersal of the human pathogenic fungus Cryptococcus. PLoS ONE 2017, 12, e0171695. [CrossRef]

36. Montagna, M.T.; De Donno, A.; Caggiano, G.; Serio, F.; De Giglio, O.; Bagordo, F.; D'Amicis, R.; Lockhart, S.R.; Cogliati, M. Molecular characterization of Cryptococcus neoformans and Cryptococcus gattii from environmental sources and genetic comparison with clinical isolates in Apulia, Italy. Environ. Res. 2018, 160, 347-352. [CrossRef] [PubMed]

37. Ponzio, V.; Chenb, Y.; Rodrigues, A.M.; Tenorb, J.L.; Toffalettib, D.L.; Medina-Pestanad, J.O.; Lopes, A.; Colombo, A.L.; Perfect, J.R. Genotypic diversity and clinical outcome of cryptococcosis in renal transplant recipients in Brazil. Emerg. Microb. Infect. 2019, 8, 119-129. [CrossRef]

38. Nyazika, T.K.; Hagen, F.; Machiridza, T.; Kutepa, M.; Masanganise, F.; Hendrickx, M.; Boekhout, T.; Magombei-Majinjiwa, T.; Siziba, N.; Chin'ombe, N.; et al. Cryptococcus neoformans population diversity and clinical outcomes of HIV-associated cryptococcal meningitis patients in Zimbabwe. J. Med. Microbiol. 2016, 65, 1281-1288. [CrossRef] [PubMed]

39. Lee, G.A.; Arthur, I.; Merritt, A.; Leung, M. Molecular types of Cryptococcus neoformans and Cryptococcus gattii in Western Australia and correlation with antifungal susceptibility. Med. Mycol. 2019. Epub ahead of print. [CrossRef] [PubMed]

40. Herkert, P.F.; Meis, J.F.; de Oliveira Salvador, G.L.; Rodrigues Gomes, R.; Aparecida Vicente, V.; Dominguez Muro, M.; Lameira Pinheiro, R.; Lopes Colombo, A.; Vargas Schwarzbold, A.; de Oliveira, C.S.; et al. Molecular characterization and antifungal susceptibility testing of Cryptococcus neoformans sensu stricto from southern Brazil. J. Med. Microbiol. 2018, 67, 560-569. [CrossRef] 